\title{
De halvedle livene i Khambhat
}

\author{
Halvedelsteiner av agat er fargerike og vakre i smykker og pyntegjen- \\ stander, men noen har gravd dem frem, stykket dem opp og polert dem. \\ Arbeiderne er utsatt for yrkessykdommer som kan ta livet av dem i løpet \\ av få år, til tross for at sykdommen kunne vært forebygd med ganske \\ enkle midler. Daglig bruker vi produktene de lager i India og Kina.
}

\section{Yogindra Samant}

yogindra.samant@arbeidstilsynet.no

Direktoratet for arbeidstilsynet

Statens Hus7468 Trondheim

\section{Ebba L. Wergeland}

Arbeidstilsynet

Oslo

Artikkelen bygger på et besøk i India hvor en av oss holdt kurs om arbeidshelse for leger og andre interessenter i den indiske delstaten Gujarat i september 2008.

Smykker av halvedelstein brukes overalt i verden, også i Norge. India og Kina er de to største eksportørene av smykker og gjenstander av halvedelstein til hele verden.

Arbeidsmiljøet er helsefarlig i begge land, men noe bedre i Kina på grunn av bedre økonomi og arbeidervern (1). Det er først og fremst bearbeiding av halvedelsteiner og krystallinsk kvarts som forkorter livet fordi arbeiderne får silikose $(2,3)$.

I tillegg til ren kvarts, bearbeides agat som er en mikrokrystallinsk variant av kvarts, en halvedelstein med karakteristisk fargerikdom. Halvedelsteinindustrien i byen Khambhat og nærområdene i den indiske delstaten Gujarat sysselsetter ca. 30000 arbeidere (4). Det er en hjemmebasert småskalaindustri (cottage industry) hvor hele familien jobber med de forskjellige prosessene. Denne formen for familiebasert næringsaktivitet kjenner vi igjen fra tidlige perioder av industrialiseringen i Europa (5).

Bearbeiding av halvedelstein har stort sett vært den eneste inntektskilden for folk i dette området i mange hundre år. Arbeidsprosessen omfatter knusing, oppvarming (gjør agatsteinen lettere å forme og forsterker fargene), sliping og polering. I hundrevis av år har arbeidsmetodene vært manuelle og antakelig forholdsvis ufarlige. Innføringen av slipemaskiner $\mathrm{i}$ industrien i 1960-årene har hatt omfattende negative konsekvenser for folkehelsen (6).

\section{En gammel fiende}

Den teknologiske utviklingen og innføring av maskiner har gjort produksjonen lettere og mer effektiv, men samtidig gitt mye større eksponering for støv. Når arbeiderne trekker støv av krystallinsk kvarts inn i lungene, oppstår det lungefibrose eller silikose (ramme 1). Det er den samme sykdommen som Ramazzini beskrev for mer enn 300 år siden som bergverksarbeidernes sykdom, og som fortkortet livet til skjærsliperne i Sheffield på 1800-tallet (6-8).

I det 16. århundre skrev Agricola om gruvearbeiderne i fjellkjeden Karpatene i Sentral-Europa, at det fantes kvinner som hadde vært gift med sju menn, fordi mennene, en etter en, fikk en forferdelig lungesott og en tidlig død (6). Det samme fortelles skremmende nok i dag om kvinner i Khambhat, hvor det også er dem som har vært gift med mange menn fordi en etter en er død av silikose (9).

National Institute of Occupational Health (Det indiske arbeidshelseinstituttet) har gjennomført en epidemiologisk studie i agatindustrien (10). Studien avdekket problemer både med arbeidsmiljø og med forurensing til omgivelsene og hjemmemiljøet. Ikke bare arbeiderne, men også familiemedlemmene deres og folk som bodde i nærområdet, var eksponert for det helsefarlige støvet $(3,10)$.

Tuberkulose er en av de store dødsårsakene i India (11). Landområder som Khambhat har høy befolkningstetthet og svak infrastruktur. De mangler rent vann og fungerende kloakksystem og har generelt dårlige hygieniske forhold. Alt dette er kjente risikofaktorer for tuberkulose i India (12). Vi vet også at silikose øker mottakeligheten for tuberkulosesmitte og dermed silikotuberkulose (ramme 1) (13). I India blir silikose ofte feildiagnostisert som tuberkulose (14). Dette fører igjen til at et ukjent antall tilfeller av silikotuberkulose blir registrert som vanlig tuberkulose og feilbehandlet (14).

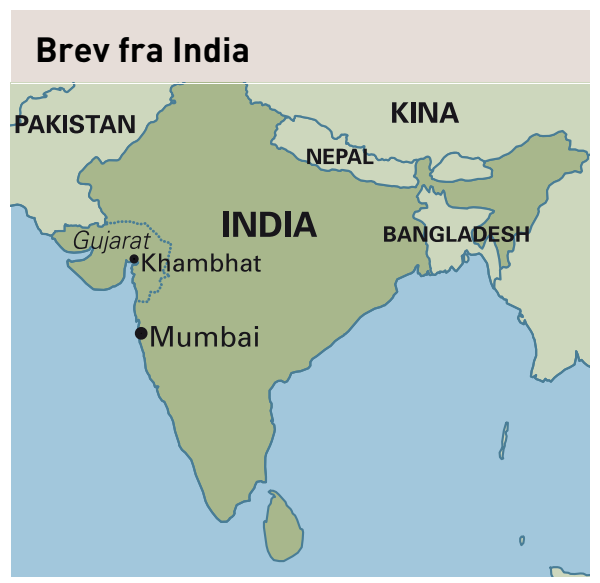

\section{Forebygging}

Veksten i produksjon og salgsinntekter fra halvedelsteinindustrien har ikke ført til bedre forhold for arbeiderne. Den beste måten å forhindre silikose på er å fjerne støvet ved kilden, for eksempel med avsug eller ved innelukking av prosessen. Renhold, ventilasjon og vannspredere kan dempe støveksponeringen. Åndedrettsvern med filter som stanser partiklene eller med frisklufttilførsel kan også gjøre nytte. Disse tiltakene er anbefalt av det indiske arbeidshelseinstituttet. Problemet er ikke hvordan man skal forebygge, men hvem som skal betale (15).

Uansett hvilke tekniske løsninger man velger, krever det investeringer, blant annet til elektrisitet. Indisk arbeidsmiljølov omfatter ikke denne typen småskalaindustri. Pro-

\section{Ramme 1}

\section{Silikose}

Innånding av støv fra krystallinsk silika fører til lungefibrose og emfysem (silikose). Man skiller mellom kronisk, akselererende eller akutt etter alvorlighetsgrad, og hvilken type som oppstår avhenger av eksponeringsgraden. I langtkomne stadier er sykdommen invalidiserende og ofte dødelig. En hyppig medvirkende dødsårsak ved silikose er lungetuberkulose (silikotuberkulose). Årsaken til den $ø$ kte mortaliteten ved silikotuberkulose 110-30 ganger høyere enn ved silikose uten tuberkulosel er ikke kjent, men det er antatt at silikatstøvet skader pulmonale makrofager og begrenser deres evne til å drepe tuberkelbasillen (6). 


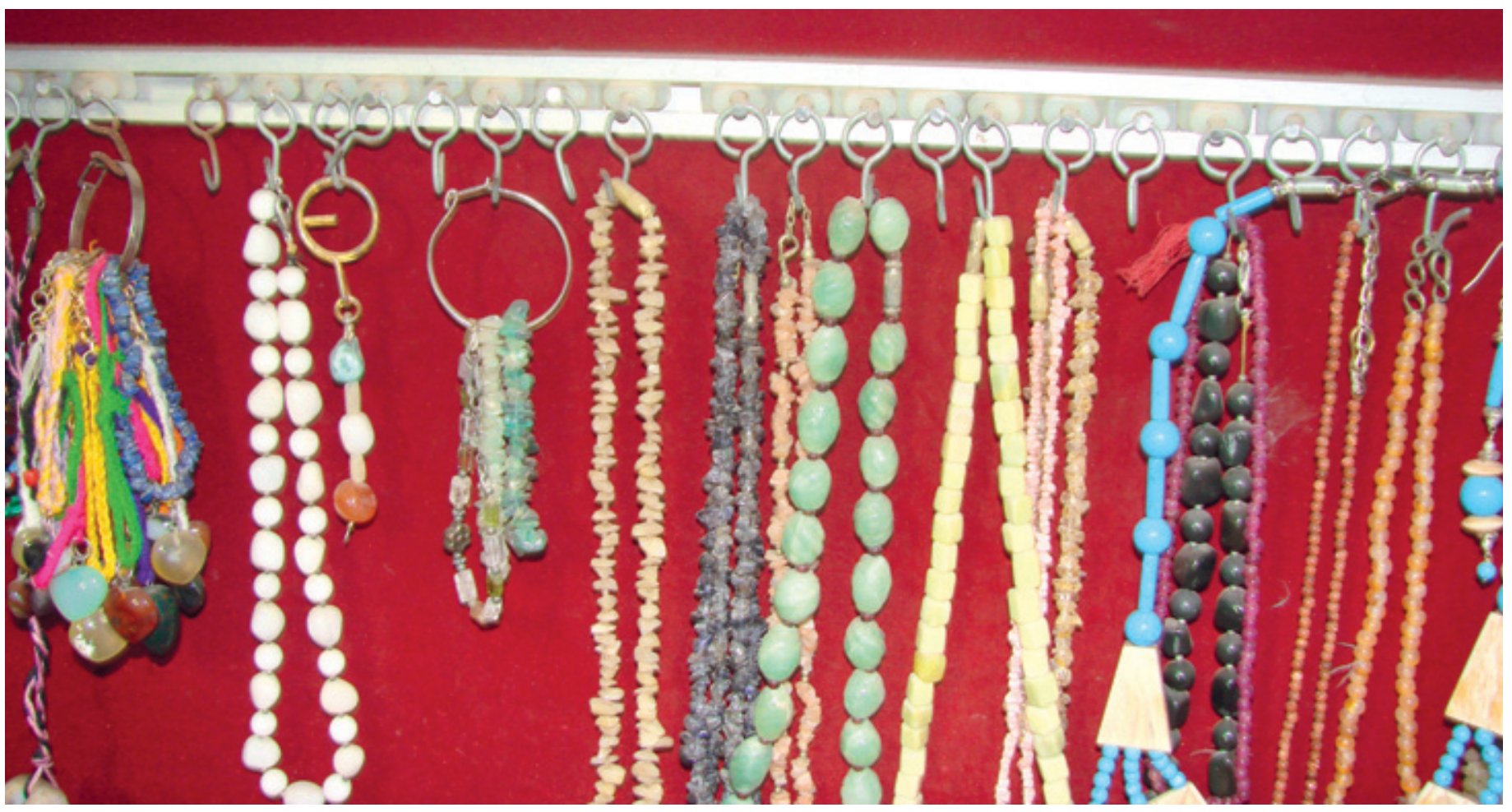

Smykkene lages av agatsteiner i forskjellige farger og former, og er meget populære både i India og andre land. Alle foto Yogindra Samant

dusentene har heller ikke noen egeninteresse av å beskytte arbeidernes helse, ettersom det alltid er nok arbeidsløse til å erstatte dem som faller fra. Det indiske arbeidshelseinstituttet foreslo i sin kostnad-nytte-analyse at produsentene skulle sette i gang tiltak i samarbeid med statlige myndigheter, men så langt har det ikke gitt resultater (15).

\section{Gjeldsfelle}

De fleste som jobber i halvedelsteinindustrien i Khambhat, er fra de laveste samfunnsklas- sene, og de har ikke fått del i Indias økonomiske vekst og fremgang. Arbeiderne er uorganiserte og dårlig betalt. De kjemper fra dag til dag for å overleve. Produsentene utnytter dem, og staten har så langt vært tvetydig i sin holdning til disse arbeiderne. Overgang til maskindrevet produksjon har vært avgjørende for å klare konkurransen i denne industrien. De fleste som driver hjemmebasert bearbeiding av stein har motordrevet verktøy. Arbeiderne er fanget $i$ en gjeldsfelle. Produsentene skaffer arbeiderne lån til å kjøpe maskiner fra dem, men betaler samtidig lønn for arbeidet som ikke nødvendigvis er i tråd med minstelønnsbestemmelsene. Og selv når produsenter tilsynelatende betaler riktig minstelønn, er ikke kostnader for lokale, strøm og utstyr inkludert. Arbeiderne kan ikke skifte oppdragsgiver før de har betalt tilbake gjelden. Det tar lang tid med den dårlige lønnen. Hvis arbeideren dør før lånet er betalt, må familien overta nedbetalingen.

Polert agatstein selges for 1 indisk rupi eller ca. 13 øre per stein i det lokale mar-
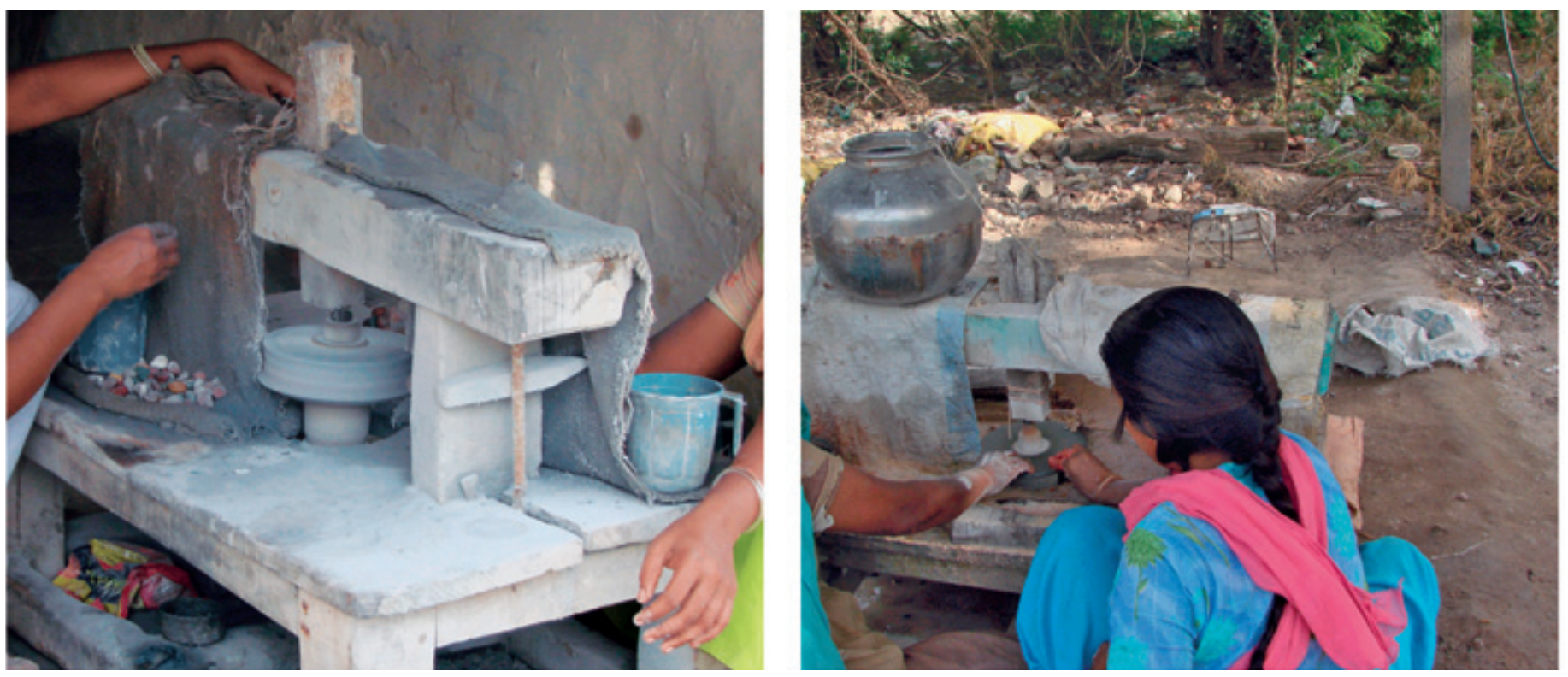

Hele familien jobber sammen. Egentlig burde de ha en elektrisk drevet vannspreder eller en elektrisk vannpumpe for å dempe støvingen, men siden strømmen er dyr, bruker de sin oppfinnsomhet og litt elementær fysikk som sikrer en stadig vannstrøm på arbeidsbordet. Men kapillærkraft og tyngdekraft er ikke nok til å gi en vannmengde som reduserer støvmengden tilstrekkelig 


\section{Ramme 2}

\section{Uformell sektor}

Uformell sektor logså omtalt som uregistrert sektor) er den delen av produksjonslivet der det produseres varer eller tjenester i små enheter med hovedformål å skaffe arbeid og inntekt til den eller dem som arbeider der. Arbeidsorganisasjonen er oftest enkel, med lite eller intet skille mellom produksjonsfaktorene: menneskelig arbeidskraft og kapital (arbeidsutstyr, naturressurser). Der det eksisterer en eier av kapitalen og et arbeidsforhold mellom eier og arbeider, er dette hovedsakelig basert på midlertidige avtaler, slektskapsforhold eller andre personlige og sosiale relasjoner i stedet for kontraktsfestede arbeidsavtaler og formelle rettigheter (17).

kedet. Produktet blir dyrere jo lenger bort fra Khambhat man kommer. En smykkestein av agat som koster 1 rupi i Khambhat, koster ti ganger mer i en storby som Mumbai, og sannsynligvis 100 ganger mer i Europa eller USA. Arbeiderne tjener 100-400 rupi per dag, avhengig av arbeidsoppgave og hvor mye de produserer. Siden arbeiderne får betalt for hver stein, tjener de bedre jo raskere de ferdigbehandler steinene. Å dyppe steinen i vann før den slipes kan redusere støveksponeringen, men det betyr tapt inntekt.

\section{Yrkesskadeerstatning}

Arbeiderne i halvedelsteinindustrien får sjelden erstatning hvis de pådrar seg silikose. Selv om produksjonen skulle være omfattet av loven, lar de fleste produsentene være å registrere seg hos arbeidsmiljømyndighetene. De kan gjøre dette uten at det får noen konsekvenser for dem.

I India som i Norge er det vanskelig å få data fra trygdeadministrasjonen om diagnosespesifikk yrkesskadeerstatning. I de nyeste nasjonale rapportene som er tilgjenglige om yrkesskadeerstatning, finner vi ikke et eneste tilfelle av yrkesskadeerstatning for silikose som er tilkjent arbeidere fra Khambhat (16).

Situasjonen er ekstra vanskelig fordi arbeidsforholdet (mellom arbeidere og oppkjøpere/produsenter) som oftest ikke er dokumentert. Dette er vanlig på landsbygda i India, hvor om lag $65 \%$ av arbeiderne er i uformelle (uregistrerte) arbeidsforhold (ramme 2) (17).

Den høye bakgrunnsprevalensen av tuberkulose gjør også at betydningen av arbeidsforholdene blir mindre synlig for myndighetene. India har den høyeste tuberkuloseprevalens i verden, og problemet er verst $\mathrm{i}$ landsbyområdene. Tuberkulosen blir ofte tilskrevet livsstilsfaktorer som røyking, tygging av tobakk, dårlig hygiene og alkoholisme. Betydningen av arbeidsmiljøet (agatstøv, kvartsstøv) er lett å overse siden fattigdom, dårlig hygiene og bruk av tobakk er så utbredt. Dermed kan sykelighet eller dødelighet som skyldes silikotuberkulose bli registrert som vanlig tuberkulose. Ansvaret individualiseres ved at sykdommen tilskrives arbeiderens vaner og hjemmemiljø. Dersom mortalitet og morbiditet av støvlungesykdom ble riktig diagnostisert som silikose eller silikotuberkulose, ville produsentenes og myndighetenes ansvar bli synliggjort.

\section{Lokale initiativer}

Bildene fra Khambhat forteller oss om skjebnen til medmennesker langt fra vår hverdag. Mange i vår del av verden kjøper disse agatproduktene uten å kjenne historien bak. Trolig er tusenvis av andre arbeidere $\mathrm{i}$ denne industrien både $\mathrm{i}$ India og Kina rammet på samme måte som arbeiderne i Khambhat.

Hele historien fra Khambhat er ikke fortalt før vi tar med at det finnes frivillige, lokale organisasjoner som arbeider for å bedre forholdene for arbeiderne, slike som Peoples Training \& Research Centre (PTRC) (18). Dette er en liten grasrotorganisasjon som jobber for bedre arbeidsmiljø for arbeiderne i delstaten Gujarat. PTRC er involvert $\mathrm{i}$ arbeidsmiljøopplæring og helsearbeid for arbeiderne, og subsidierer barnehage og gratis mat til de etterlatte etter agatarbeiderne. De samler også inn dokumentasjon om forholdene, og forskningsresultater fra agatindustrien. De samarbeider med the Asian Network for Rights of Occupational Accident Victims (ANROAV), en stor koalisjon av yrkesskadede arbeidere, fagforeninger og andre arbeidsgrupper over hele Asia, med kontor på Filippinene. ANROAV arbeider for å styrke de yrkesskadedes rettigheter og forbedre arbeidsforholdene (19).

I tillegg til å støtte slike organisasjoner økonomisk, vil vi anbefale interesserte leger og medisinstudenter i Norge å besøke PTRC og andre lokale initiativer, delta i feltarbeidet deres og lære om global helse og yrkeshygiene fra en annen vinkel enn den vi vanligvis får i vår del av verden.

Vi takker Arbeidstilsynet som finansierte et arbeidshelsekurs for leger i Gujarat, og dermed ga en av oss (YS) anledning til å besøke Khambhat sammen med PTRC under en privat reise til India.

Oppgitte interessekonflikter: Ingen

\section{Litteratur}

1. Leonard TM. The encyclopaedia of the developing world. New York: Routledge, Taylor \& Francis, 2006: 386

2. Rastogi SK, Gupta BN, Chandra H et al. A study of the prevalence of respiratory morbidity among agate workers. Int Arch Occup Environ Health 1991; 63: 21-6.

3. Jiang CQ, Xiao LW, Lam TH et al. Accelerated silicosis in workers exposed to agate dust in Guangzhou, China. Am J Ind Med 2001; 40: 87-91.
4. Silicosis - a death trap for agate workers in Gujarat. Gujarat, India: PUCL, 2007. www. countercurrents.org/pucl021107.htm (14.12.2009).

5. Tuttle C. Child labor during the British industrial revolution. Economic history. Net Encyclopedia, edited by Robert Whaples, 2001. http://eh.net/ encyclopedia/article/tuttle.labor.child.britain (25.12.2009).

6. WHO. Fact sheet: silicosis. Genève: World Health Organization, 2000. www.who.int/mediacentre/ factsheets/fs238/en/ (6.11.2009).

7. Ramazzini B. De morbis artificum diatriba: diseases of workers med oversettelse ved Wilmer Cave Wright. Chicago: University of Chicago Press, 1940.

8. Hall J. On prevention \& treatment of Sheffield's grinder's disease. Quart J Med Surg 1857; 20 : $1-52$.

9. Way to dusty death. Dokumentarfilm produsert av riks-TV i India (Doordarshan). New Delhi, India: RGB Films, 2007. www.rgb-films.org/frmplayvideo.aspx? scrFile=nDTUxXC748w\&Videold $=26$ (6.1.2010).

10. Bhagia LJ, Parikh DJ, Sadhu HG. Ambient silica monitoring in vicinity of agate industry, Khambhat, India. Ind J Occup Hyg Safety 2007; 1: 6-10.

11. Tuberculosis control India. Tuberculosis key facts. India: Directorate General of Health Services, 2009. www.tbcindia.org/key.asp (6.11.2009).

12. Agnihotram R. Respiratory disease burden in rural India - a review from multiple data sources. The Internet J Epid 2005; 2. www.ispub.com/journal/ the_internet_journal_of_epidemiology/volume 2_number_2_13/article/respiratory_disease burden_in_rural_india_a_review_from_multiple data_sources.html (6.11.2009).

13. NIOSH Hazard Review. Health effects of occupational exposure to respirable silica. Atlanta, GA: Centers for Disease Control and Prevention, 2009 www.cdc.gov/niosh/docs/2002-129/02-129A.html (6.1.2010).

14. Legislative provisions relating to silica exposure and silicosis in India: The need for review. San Francisco, CA: Occupational Knowledge International, 2009. www.okinternational.org/docs/ Silica\%20Legislative\%20Review.pdf (5.1.2010).

15. Bhagia LJ, Parikh DJ, Sadhu HG. Cost-benefit analysis of installing dust control devices in the agate industry, Khambhat. Ind J Occup Environ Med 2008; 12: 128-31.

16. Pocket book of labour statistics 2006. New Delhi: Govt of India, 2006.

17. Organisation for Economic Cooperation and Development (OECD STAT Extracts). Glossary of statistical terms. http://stats.oecd.org/glossary/detail. asp?ID=1350 (6.11.2009)

18. Peoples Training \& Research Centre (PTRC). http://ptrc.info/ (6.11. 2009)

19. Asian network for rights of occupational accidents victims (ANROAV). http://anroav.org/ (6.11.2009).

Manuskriptet ble mottatt 30.11. 2009 og godkjent 11.2. 2010. Medisinsk redaktør Siri Lunde. 